\title{
Alcohol-Induced Coma, Hypothermia and Hypotension
}

\section{Klaric $\mathrm{D}^{1 *}$ and Klaric $\mathrm{V}^{2}$}

${ }^{1}$ Department of Dialysis, Zadar Geneal Hospital, Zadar, Croatia

${ }^{2}$ Department of Psychiatry, Zadar General Hospital, Zadar, Croatia

\begin{abstract}
Objectives: Coma, hypothermia and hypotension caused by alcohol and benzodiazepine intoxication can be successfully treated with the use of continuous veno-venous hemodialysis (CVVHD). It eliminates small molecules, corrects pathological laboratory parameters and gradually heats the blood.

Methods: We present a case report of a female patient suffering from depression who attempted suicide with benzodiazepine, karbamazepine and alcohol ingestion. She was brought into the intensive care unit in a comatous state (GCS score-3), with an arterial blood pressure of approximately $40 \mathrm{mmHg}$, body temperature less than $30^{\circ} \mathrm{C}$, blood alcohol concentration of $550 \mathrm{mg} / \mathrm{dL}$, and positive assessments for benzodiazepines and karbamazepine. The nefrologist indicates that CVVHD is necessary.

Results: Alcohol blood levels fell to $170 \mathrm{mg} / \mathrm{dL}$ after 10 hours of CVVHD, while blood pressure and body temperature rose. After CVVHD, alcohol blood levels dropped to $0.002 \mathrm{mg} / \mathrm{dL}$, body temperature measured $35.5^{\circ} \mathrm{C}$, and blood pressure, diuresis and electrolite status were of normal levels.

Conclusion: CVVHD (along with measures of intensive treatment) had a positive outcome on a patient that was vitally endangered by suicide attempt. This is based on the fact that CVVHD gives adequate clearance of alcohol and benzodiazepines, corrects electrolite status, and gradually raises body temperature by extracorporal circulation.
\end{abstract}

Keywords:

Alcoholic coma; Hypothermia; Hypotension;

Hemodialysis

\section{Introduction}

Alcohol-induced coma, hypothermia and hypotension are a result of a chain of events, including vasodilatation of central origin, and hypoglycemia due to a decrease in muscle glicogen stores. Hypothermia carries a high risk of mortality, most commonly associated with cardiac arrhythmia, and one of the most successful ways of treating hypothermia in vital indications is hemodialysis. In addition, hemodialysis can be an option in treatment of accidental poisoning or attempted suicide using alchohol, especially if the intoxication is combined with other vitally endangering conditions, such as coma, osmolality imbalance, hypothermia, acidosis, etc.

\section{Case Report}

A 65 year old woman in a coma was accepted at the emergency ward. Upon admission, the patient was unconscious, cyanotic, with occasional shallow respiration and without palpable arterial pulsations. Her pupils were dilated with no pupillary light reflex, as well as being in total areflexia. Her blood pressure was undetectable, as well as the rectal temperature. The ECG registered sinus bradycardia with a frequency of $40 \mathrm{bpm}$.

She was immediately intubated and connected to a respirator for mechanical ventilation, and she was given electrolite and coloid solutions, after which her blood pressure was still unmeasurable. Because of this, invasive arterial blood pressure measuring was indicated, which measured roughly $40 \mathrm{mmHg}$, as well as a central venous catheter. Body temperature was less than $30^{\circ} \mathrm{C}$, and diuresis was $0 \mathrm{~mL} / \mathrm{h}$.

Blood samples were drawn for laboratory measurements. A cerebral CT-scan was done as well. The scan showed cerebral parenchyma of normal attenuation, without visible focal lesions, and of symmetrical central structures.

\section{Laboratory measurements}

Osmolality - 272 mOsm; $\mathrm{pH}-7.2 ; \mathrm{pCO}_{2}-3.70 \mathrm{mmHg} ; \mathrm{HCO}_{3}$ - $13.0 \mathrm{mmol} / \mathrm{L} ; \mathrm{BE}-11 \mathrm{mmol} / \mathrm{L} ; \mathrm{Na}-135 \mathrm{mmol} / \mathrm{L} ; \mathrm{K}-3.8 \mathrm{mmol} / \mathrm{L}$; $\mathrm{Cl}-103 \mathrm{mmol} / \mathrm{L} ; \mathrm{Ca}-1.52 \mathrm{mmol} / \mathrm{L} ;$ Glucose $-4.1 \mathrm{mmol} / \mathrm{L} ; \mathrm{E}-$ $3.73 \times 10^{12} / \mathrm{L} ; \mathrm{Hb}-108 \mathrm{~g} / \mathrm{L} ; \mathrm{L}-4.97 \times 10^{9} / \mathrm{L}$; creatinine $-87 \mu \mathrm{mol} / \mathrm{L}$; urea - $3.6 \mathrm{mmol} / \mathrm{L}$; AST - $129 \mathrm{U} / \mathrm{L} ; \mathrm{ALT}$ - $37 \mathrm{U} / \mathrm{L}$; Troponin - $0.0 \mathrm{~g} / \mathrm{L}$; bilirubin $-4.4 \mu \mathrm{mol} / \mathrm{L}$; coagulogram was normal.

Toxicology measurements attain a serum alcohol concentration of $550 \mathrm{mg} / \mathrm{dL}, 363.8 \mathrm{ng} / \mathrm{mL}$ of benzodiazepines in the urine, as well as $35.7 \mu \mathrm{g} / \mathrm{mL}$ of karbamazepines in the urine. Parallel with this, measures of warming and vasoactive support are carried out, as well as gastric lavage and usage of activated charcoal.

\section{Neurological assessment}

Patient in comatous state, with dilated pupils, negative pupil light reflex, without nuchal rigidity, absence of reflexes of the limbs. Passive elevation of upper and lower extremities result in flaccid collapsing of the same.

A nefrologist was consulted in regards to the high blood alcohol concentration, who indicated hemodialyis because of the high serum concentration of alcohol, hypothermia and acidosis. The continuous method was selected, with a high-flux filter (membrane polysulfone,

*Corresponding authors: Dragan Klarić, MD, Zadar General Hospital, Boze Pericica 5, 23000 Zadar, Croatia, Tel: 00385-23-505121; E-mail: dragan.klaric@zd.t-com.hr

Received August 07, 2015; Accepted November 16, 2015; Published November 18, 2015

Citation: Klaric D, Klaric V (2015) Alcohol-Induced Coma, Hypothermia and Hypotension. J Membra Sci Technol 5: 137. doi:10.4172/2155-9589.1000137

Copyright: @ 2015 Klaric D, et al. This is an open-access article distributed under the terms of the Creative Commons Attribution License, which permits unrestricted use, distribution, and reproduction in any medium, provided the original author and source are credited. 
surface area: $1.5 \mathrm{~m}^{2}$ ), the dialysate flow being $500-1200 \mathrm{~mL} / \mathrm{h}$, whilst blood flow was $100-120 \mathrm{~mL} / \mathrm{min}$, with dialysate temperature gradually increasing to physiological values. The ultrafiltration ratio was zero. Antithrombotic therapy was given as well: low molecular weight heparin (nandroparine-calcium) in a dose of 3800 anti-Xa IU. The total duration of the procedure was 18 hours. The concentration of alcohol in the serum after 10 hours of hemodialysis equalled 170 $\mathrm{mg} / \mathrm{dL}$, which urged prolonging of the process up to 18 hours. The concentration of alcohol in the dialysate was $20.8 \mathrm{mg} / \mathrm{dL}$. hemodialysis is also indicated for carbamazepine intoxication, as stated recently by the Extracoroporeal Treatments in Poisoning working group (Table 1 and Figure 1).

On the second day upon admission, rehydration was proceeded with control of the central venous pressure (CVP), as well as administration of adequate doses of dopamin upon which diuresis is established. Blood pressure and body temperature significantly improve.

\section{Neurological reassessment}

The patient does not open her eyes upon verbal order, reacts to painful stimulii by moving of the extremities in a symmetrically identical fashion. Isocoric pupils, with normal pupil light reflex, absence of nuchal rigidity, other cranial nerve functioning is normal.

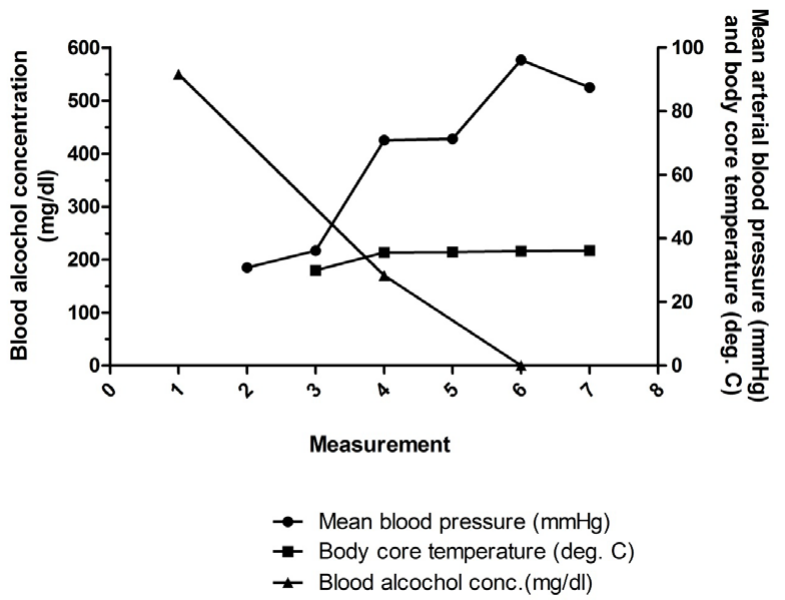

Figure 1: Changes in mean arterial blood pressure, body core temperature and blood alcochol level during hemodialysis course.
Stretch reflexes are symmetrical and normal. Bilateral impure plantar response. The EEG is diffusely slowered and changed in an encephalopathic pattern with epileptogenic graphoelements located in the left frontotemporal region.

\section{Control chest radiogram}

Inhomogenous infiltrate located parahilar left. Fracture of the 5th and 6th rib with minor shift of fragments.

As the radiogram results are accompanied by the rise in nonsegmented leukocytes, amoxicillin + clavulonic acid is added to the overall therapy.

The patient started gaining consciousness, and in the evening is fully conscious, after which she is detached from the respirator and is extubated. Vasoactive support is cancelled, her vital signs and parameters were in normal range, and enteral feeding was reestablished, as well. She was often given Dolantin for analgesia of back pain, and high dosage of Dormicum because of anxiety.

\section{First psychiatric assessment}

During the interview, the patient is calm. However, she states that she is not doing well mentally, she is always tense and anxious. She has been consuming anxiolytics for some time now, and she started consuming alcohol as well. She is of depressed affect and had attempted suicide. Sleeping disorders are also present.

Th: Dormicum ex. Helex $3 \times 0.5 \mathrm{mg}$, Zoloft $50 \mathrm{mg}$, Prazine 50 $\mathrm{mg}+50 \mathrm{mg}+100 \mathrm{mg}$.

\section{Discussion}

Maximum concentrations of alcohol in the serum are attained 6 hours after ingestion. Ethanol intoxication can lead to morbidity or death in various ways. The main effect ethanol has on the central nervous system is depressor. On the cellular level, ethanol increases gama-amino butyric acid (GABA) activity, acting on the GABA-A receptors as do benzodiazepines [1,2], having an additive effect when taken together. Ethanol also multiplies the depressor effect, sometimes having dangerous consequences, of many medicaments that effect the central nervous system, such as antidepressives, antipsychotics and opiates $[1,3]$.

The mentioned alcohol concentrations can be fatal, which call for urgent intervention. Hypotension and hypothermia are direct outcomes of alcoholic intoxication. In this case, considering the

\begin{tabular}{|c|c|c|c|c|c|c|c|c|c|c|}
\hline \multirow{2}{*}{\begin{tabular}{|l|}
$\begin{array}{l}\text { Time } \\
\text { (hours) }\end{array}$ \\
Start \\
\end{tabular}} & \multirow{2}{*}{$\begin{array}{l}\text { CVP } \\
+8\end{array}$} & \multirow{2}{*}{$\begin{array}{c}\text { BP/C } \\
0\end{array}$} & \multirow{2}{*}{$\begin{array}{c}\text { Pulse } \\
40\end{array}$} & \multirow{2}{*}{$\begin{array}{c}\text { Temp. } \\
\left({ }^{\circ} \mathbf{C}\right) \\
0\end{array}$} & \multirow{2}{*}{$\begin{array}{c}\mathrm{O}_{2} \text { sat. (\%) } \\
64\end{array}$} & \multirow{2}{*}{$\begin{array}{c}\begin{array}{c}\text { Diuresis } \\
\text { (mL/h) }\end{array} \\
0\end{array}$} & \multirow{2}{*}{$\begin{array}{c}\begin{array}{c}\text { BAC } \\
\text { (mg/dL) }\end{array} \\
550\end{array}$} & \multicolumn{2}{|c|}{ Interventions } & \multirow{2}{*}{$\begin{array}{c}\text { Urine toxicology } \\
\text { Benzodiapines } 363.8 \mathrm{ng} / \mathrm{ml}\end{array}$} \\
\hline & & & & & & & & Intubation Respirator & $\begin{array}{l}\text { Chest X-ray } \\
\text { MSCT, EEG }\end{array}$ & \\
\hline $21-22$ & +8 & 0 & 45 & 0 & 68 & 0 & & ABS line Dialysis & & Carbamazepine $35.7 \mu \mathrm{g} / \mathrm{ml}$ \\
\hline $23-24$ & +8 & $47-23$ & 54 & $\mathrm{~T} / \mathrm{C}$ & 96 & 0 & & & & \\
\hline $24-07$ & & $49-30$ & 56 & $\downarrow 30$ & 95 & 0 & & & & \\
\hline $07-12$ & +17 & $97-59$ & 82 & 35.6 & 97 & 100 & 170 & EEG & $\begin{array}{l}\text { Chest X-ray } \\
\text { pneumoniae }\end{array}$ & \\
\hline $12-16$ & +12 & $100-58$ & 96 & 35.7 & 94 & $15-50$ & & Stop dialysis & & \\
\hline $16-21$ & +12 & $130-80$ & 104 & 36 & 95 & $60-100$ & 0.02 & & & \\
\hline 21 & +12 & $124-70$ & 107 & 36.1 & 95 & $60-100$ & & Extubation & & \\
\hline
\end{tabular}

CVP - central venous pressure $\mathrm{mmH}_{2} \mathrm{O}$

$\mathrm{BP} / \mathrm{C}$ - blood pressure central measurement

$\mathrm{T} / \mathrm{C}$ - temperature central measurement

$\mathrm{BAC}$ - blood alcohol concentration 
Citation: Klaric D, Klaric V (2015) Alcohol-Induced Coma, Hypothermia and Hypotension. J Membra Sci Technol 5: 137. doi:10.4172/21559589.1000137

Page 3 of 3

psychiatrist's assessment, the patient was a 'tolerant' alcoholic, who frequently abused alcohol and benzodiazepines. The excess of the abusives led to coma, respiratory insufficiency and circulatory collapse. We chose to prolong the dialysis treatment considering the patient's state of hypothermia and the need for gradual body temperature elevation, with expected slower ethanol clearance rate. Hemodialysis, as well as peritoneal dialysis, is a fast and efficient approach to internal warming, whereas external warming can theoretically cause cooling of body temperature and other complications [4-6].

Hemodialysis can recuperate body temperature faster by directly warming blood via extracorporal heater. Hemodialysis is also a faster and more efficient variant of alcohol elimination than gastric lavage. Because hemodialysis is a relatively simple therapeutic method available in the majority of hospitals, it should be preferred to other methods where intoxication is accompanied with hypothermia, acidosis and electrolyte imbalance. However, frequent complications in the respiratory tract are bronchoaspiration and bronchopneumonia [7-9].

\section{Psychiatrist's Opinion}

The patient is a long term benzodiazepine addict, consuming diazepam. Over time, she started abusing diazepam more frequently, which she combined with alcohol. She had suffered from depression for a long time without seeking medical attention. She was functioning normally at work, but not socially and at home. She attempted suicide because of extreme inner tension, anxiety, lack of hope and perspective.

Even though the outcome of the acute intoxication came out to be successful, psychiatric therapy is required because of the structure of the patient's personality (having elements of narcism), depression and addiction. Her depression wasn't treated correctly since she hadn't seeked for the help of a psychiatrist.

\section{Conclusion}

Hypothermia in acute alcohol intoxication is caused by vasodilation and the depressory effect of alchohol. The progress of hypothermia is provoked by low energy intake, hypoglycaemia and low glicogen reserves [2].

The purpose of this work was to enlighten the importance of CVVHD in acute intoxication of the mentioned substances accompanied by deep coma (GCS score-3) and hypothermia.

\section{References}

1. Klaric V, Klaric D (2014) Alcohol coma and hypothermia. Royal College of Psychiatrists International Congress, London.

2. Gamulin S, Marušić $M$, Kovač Z (2006) Pathophysiology - basic mechanisms of disease - textbook, book one. Disorders of thermoregulation - aciden induced hypothaermia.

3. Rang HP, Dale MM, Ritter JM, Moore PK (2003) Medicament addiction and abuse of medicaments. Churchill Livingstone.

4. Soung LS, Swank L, Ing TS, Said RA, Goldman JW, et al. (1977) Treatment of accidental hypothermia with peritoneal dialysis. Can Med Assoc J 117: 14151416.

5. Zafren K, Mechen CC, Danzl DF, Grayzel J (2015) Accidental hypothermia in adults.

6. Golper TA (2013) Use of peritoneal dialysis for the treatment of acute kidney injury (acute renal failure) [Internet].

7. Naheed A (2007) Peritoneal Dialysis in Renal Replacement Therapy for Patients with Acute Kidney Injury. Nephrol Dial Transplant 22: 2991-2998.

8. Lage C, Pischetsrieder M, Aufricht C, Jorres A, Schilling H, et al. (2000) First in vitro in vivo experiences with stay. Safe balance, a pH-neutral solution in a dual-chambered bag. Perit Dial Int 20: S28-32.

9. Ghannoum M, Yates C, Galvao TF, Sowinski KM, Vo TH, et al. (2014) Extracorporeal treatment for carbamazepine poisoning: systematic review and recommendations from the EXTRIP workgroup Clin Toxicol (Phila) 52: 9931004. 